\title{
Every Leadership in the wild \\ Librarian \\ blue yonder
}

a Leader

\author{
By Maryhelen Jones
}

\section{Academic librarians partner with Air Force educators and librarians}

$\boldsymbol{0}$ ne of the most challenging "librarian-cumleader" situations each of us may professionally face is the use of our particular experience and knowledge in another organizational culture. A small number of academic librarians, now numbering about 15 , have been involved in such expertise portability with United States Air Force educators and librarians since January 1992 through the Air Force's Quality Education System (QES) process.

Quality initiatives are being implemented in many organizational cultures including higher education, business, government, and, not surprisingly, the military. The literature of our own profession continually reflects the impact the quality movement has had on many of our own operations. In the Air Force, the QES process focuses on off-duty voluntary education programs at the installation (base) level. "Off-duty voluntary education" is not a familiar term to most academic librarians; however, it simply refers to any post-secondary, credit-bearing education program (undergraduate through doctoral) in which enlisted or officer-level military personnel participate by choice, not assignment. Unless you are an academic librarian involved with a collegiate institution offering courses and programs to the military, this whole area of higher education as "provider" to the military may be largely invisible to you.

\section{Partners in education}

At the heart of the QES process is the concept of using a defined group of educational partners who will make continuous improvements specific to their own base-level situation. In this model, the voluntary education activities of each installation are viewed holistically (hence the "partnership" concept) rather than having each collegiate program operating without regard to the other institutions that are also offering programs on the base. The QES process identifies, involves, and assists the individuals and organizations responsible for delivering a quality education experience to all students. In doing so, QES seeks to foster a culture for continuous improvement opportunities in education programs, staff, and facilities on the base, including library support and services.

Realistically, the partnership functions when a base's education services officer, his or her guidance counselors, all institutional program administrators, the base librarian, and selected others representing such areas as telecommunications meet regularly and formally to discuss common concerns, tackle problems, and develop initiatives which improve the quality of the education experience at the base.

For the Air Force, QES is a structured academic review process. It is not an accreditation process nor a military inspection. However, it both complements and goes beyond regional accreditation agency standards in its utilization of a specific set of Air Force-developed standards tied to quantified measurements. These standards deal with faculty, course and program effectiveness, counseling, student services, computers, and library support to name a few.

\section{Beginning with self-study}

One of the critical elements of the QES review process is a set of self-study documents prepared at the beginning of the process by the installation's Education Center, each college and/or university operating on the base, and

Marybelen Jones is director of Off-Campus Library Services at Central Micbigan University; e-mail: marybelen.jones@cmich.edu. She bas been involved witb QES since it began and has participated in four base visits to date. 
the base librarian. Collectively, these documents form the "Base Self-Study." Preparation of these reports is guided by the use of a QES "Assessment Guide" containing guidance on partnership formation and activities, expectations as to partnership cooperation, and a number of specific standards for key installation and institution educational functions and areas. The "Base Self-Study" plus additional information and data such as course schedules, faculty resumes, student enrollment, and completion rates, as well as institutional bulletins and reports prepares the QES Site Team for an onsite visit to access the strengths and weaknesses of the base's educational environment and offerings.

Enter the academic librarian team member; he or she joins other preselected academics for the on-site visit. Depending on the number of institutions serving the installation being visited, the team may consist of between five and seven individuals representing both higher education and the Air Force. Typically, the team has a chair, an administrator or faculty member from a collegiate institution who has gained experience with QES by serving on a previous team; three professional collegiate educators and/or administra-

tors representing the three levels (associate, baccalaureate, and graduate degrees) normally offered on a base; an academic librarian; an Air Force education services officer from a previously QES-reviewed base; and a representative from the "Major Command" under which the base organizationally falls due to its primary mission (e.g., Air Combat Command, Air Force Space Command, Air Education and Training Command, etc.). The command representative helps the civilian team members understand Air Force terminology, policies, procedures, funding, organizational reporting relationships, and military culture as they relate to higher education.

The length of time a team spends visiting the base depends on the number of collegiate institutions that may offer programs on base. A small base usually has three or four institutions; a large base, five to seven. Typically, a team will spend no more than a maximum of four days on site. During this time, each of the academics is assigned either one or two institutions to review as their primary assignment.

\section{The academic librarian's assignment}

However, the academic librarian crosscuts the various groups forming the partnership and has a much more complex and logistically challenging assignment. In the QES process, the team librarian has primary responsibility for reviewing library resources and services offered by the Base Library and each institution's library as they are used to support voluntary education at the base.

During the stay, the librarian team member will visit the base library and have at least one in-depth appointment with the base librarian and possibly the reference specialist; will speak with each institutional representative, as well as faculty and students affiliated with the institution; will talk either in person or by telephone with each institution's off-campus librarian; and will discuss library support with Education Center personnel. Depending on the particular interview, the academic librarian generally will

\section{However, the academic librarian crosscuts the various groups forming the partnership and has a much more complex and logistically challenging assignment.}

be discussing five broad categories of library resources and services:

- Collections: books, journals, CD-ROMs, software, etc.

- Services: reference assistance, ILL, access to online public access catalogs, online and CDROM databases, library instruction, etc.

- Personnel: staffing levels, vacancies, training, professional development

- Equipment: photocopiers, fax machines, personal computers

- Facilities: proximity to classrooms, operating hours/space/study areas, etc.

The academic librarian is also interested in the organizational interface the base and institutional libraries have established with the students and faculty they are serving and with each other. Depending on the individual interviewed, the team librarian will ask such questions as:

- How does the library determine what services and materials students and faculty need?

- How does the library provide services and materials to faculty and students? 
- How does the library communicate the nature, scope, and availability of library services and materials to students and faculty?

- How does the library contribute as a partner to the educational partnership?

- How does the library evaluate the efficacy of its instruction, services, outreach, etc.?

\section{Making a feam report}

As the team librarian conducts on-site interviews and reflects on the information previously provided in the self-study materials, he or she begins to formulate a series of library-related "commendations" and "recommendations" for discussion with other team members. These will be directed to both the Base Library and each institution in the final, written team report. In the report, base and institution library commendations will reflect areas of strength such as bibliographic instruction, computer connectivity, or rapid document-delivery services. Recommendations will address areas in which the

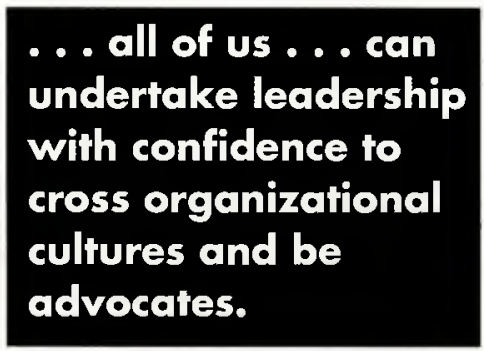

\section{Crossing organizational culfures}

From January 1992 through July 1995, 24 QES visits have been conducted, each with an academic librarian as a team member. More importantly, the changes recommended to both base libraries and institution libraries have had demonstrable results. For example, in Air Combat Command alone, where the QES process began, base library automation enhancements have totalled approximately $\$ 2.4$ million and institutional increases supporting base libraries have reached half a million dollars.

How does the Air Force QES process fit Patricia Senn Breivik's "Every Librarian a Leader" theme, team thinks either short- or long-term improvements need to be made in areas such as facilities, collection gaps or datedness in subject materials to support specific curricular offerings, or staffing deficiencies.

Throughout the visit, team members consult intensively with each other on their findings. They share areas where they believe more information is needed and try to analyze discrepancies between what has been provided in self-study documents and what they have learned through personal meetings. The team librarian is involved in all these meetings and is a full discussant on all commendations and recommendations that are being considered in all review areas, During the visit, each member also is writing/revising a draft of the report sections for which they have responsibility. For the librarian, this includes sections on the Base Library, each institution's library programs, and a cooperative efforts section addressing the overall level and use of library resources at the base.

At the conclusion of the visit, the team conducts a series of verbal out briefings to the base's senior leadership, the institutions, the Base Library staff, and Education Center personnel. These briefings cover the team's findings, especially commendations and recommendations. especially when such a small group of academic librarians has been involved? In answering this, I am reminded of part of the exchange that appeared in the October "Every Librarian a Leader" column. In it, Melvin R. George asked Karyle Butcher, "Do Librarians have knowledge that might be appropriate to share with colleagues elsewhere on campus?" Butcher answered, "Clearly we do." George went on to say, "On a more subtle level, but one which, in the long run, will prove imminently useful as we form partnerships across campus, is that as a profession we advocate for all."

Even though that exchange focused on broadening campus impact, all of us experienced in serving higher education-academic librarians, Air Force librarians, and unnamed others-can undertake leadership with confidence to cross organizational cultures and be advocates. This is exactly what happens every time a librarian participates in a team enterprise consisting of nonlibrarians. The Air Force QES process, exciting and expanding as it is for those of us who have been involved in it, is but one example of the professional capabilities we can bring to other academic-related settings. For every librarian there can be a leadership context. QES is but one of them. 
Subscribe to this unprecedented reference if you seek to lake advanlage of the Internet for your library's needs!

\title{
Internet Reference Services Quarterly
}

\author{
the journal of innovative information practice. \\ lechnologies, and resources
}

\section{Editor: Lyn Elizabeth M. Martin, MLS}

Senior Assistant Librarian and Calaloger, Learning Resources Center.

State University of New York ISUNYi. Cobleskill

Book Review Editor: Heather Blenkinsopp. MLS, MS

\section{"AT LAST, A PRINT MAP FOR EXPLOR-} INC THE REFERENCE QUADRANT OF THE INTERNET UNIVERSE. This journal will serve as a guide for those librarians and information scientists who are redefining libraries and library services."

James W. Calloway. PhD. Assistant Director of Libraries for Researeh Services,

Texas Woman's University

$\mathbf{T}$ his new journal will he the key to practical and theoretical applications and resources of the Internet for all aspects of Iıbrarianship: aumınistratıve services, reference services, interlibrary loan, acquisitions, collection development. bibliographic instruction,

cataloging. etc., as practiced in all types (research, academic, public, school, special, and corporate) and all sizes (large to small, even one person) of libraries.

Topics in the Internet Reference Services Quarterly will open new channels of information as articles will highlighi theoretical, research. and practical application of Internet-related information services, sources, and resources. A book review section is planned to give both full. length, feature reviews and short, synopsis reviews on Internet-related monographs and serials of growing interest to librarians and libraries.

The llaworth Press, inc.

10 Alice Street. Binghamton. NY $13904-1580$ Jel: 1-800-342-8678/fox 1-800-895-0582 / E mall getinfoenoworth.com

\section{Contributions Welcome...}

Potential authors should contact the editor via E-mail for a detailed "Instructions for Authors" brochure: martinlm@snycob.cobleskill.edu, or via mail or telephone: Lyn Élizabeth M. Martin. MLS. Senior Assistant Librarian and Cataloger. L.RC/Jared Van Wagenen Mall, SUNY Cobleskill, Cobleskill, NY 12043; Tel: (518) 234-5887.

\section{A Breadth of Toplcs...}

Selected Contents from Volume I:

Using the Internet for Document Delivery

Use of the Internet via Universal Inlormation Access Workstation

Wiring the Trenches: Teaching Praculty and Librarians Workıng Together on the Internet

Using World Wide Web Soltware fur Reference and Instruction

Rare Bouk Catalogers and the Internet

The Impact on Relerence Services of Networking CD.ROM Dalabases

Selling the Home Page An Fssay on the World Wide Web and Rhetoric

Empowering Women: Creating a Women's Presence on the Web

Inlernet Training: The Trainees' Thoughts

Volume 1, No. 1-Spring 1996. Quarterly (4 issues) Volume 2, No. 1-Spring 1997. Quarterly (4 issues). Subscription rates (per volume):

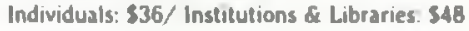

SAMPLE COPIES OF JOURNALS ARE AVALABLE MEE OF CHAMCE ia librane Plean send your reguest on youl

inditulisund Letterthed is Sample Copy Depariment. The Hawowith Piess. Inc 10 Alice Sirret. Binghamion. NY 13904 - ISSO USA
(1) 


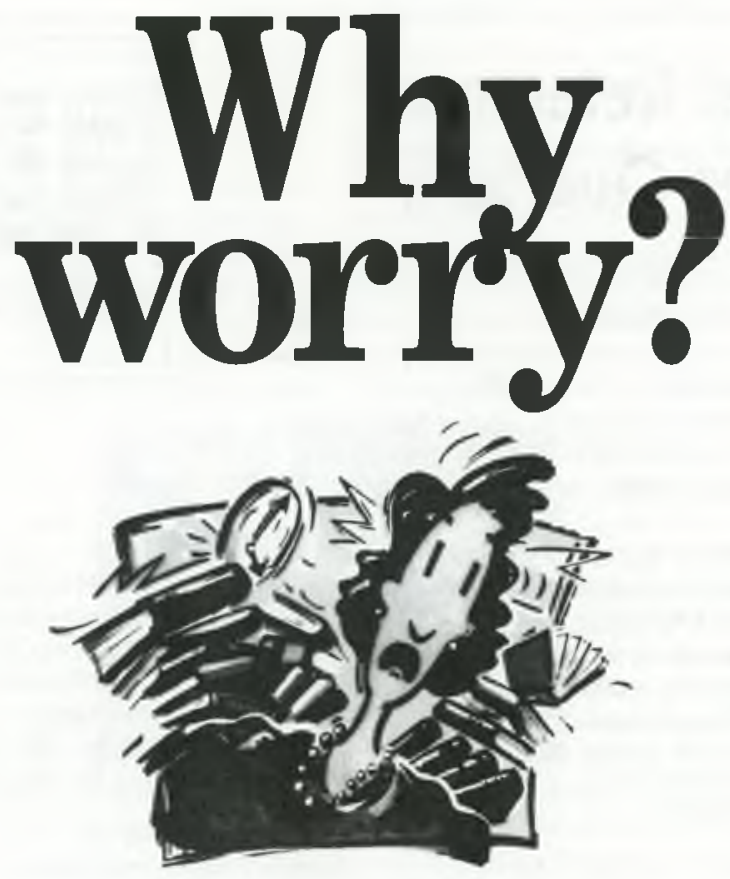

You don't have to. No longer will your staff have to process, catalog, or prepare books for the shelf under tight budget constraints and shrinking resources. Just one call to Baker \& Taylor and we'll do it all. Our librarians are experienced with providing cataloging and processing to meet your exact requirements and we can do it for less than it costs to do it yourself. Today there's a buzzword for it-“outsourcing." But at Baker \& Taylor it's not new and it's not a buzzword-we've been providing shelf-ready books for almost 30 years. In fact, our customers think of us as colleagues-not just a book supplier So, why worry? Call Baker \& Taylor.

For more details about our selection, acquisition and technical services, please call Information Services at 1-800-775-1800.

\section{BAKER\&TAYLOR}

